\title{
El humor es cosa seria. Discursos transgresores en la prensa alternativa norpatagónica
}

\section{Humour is a serious matter. Transgression discourses in the alternative press of the North of Patagonia}

María Palmira Massi

Universidad Nacional del Comahue

mpmassi@fibertel.com.ar

\section{Resumen}

En la actualidad, en el norte de la Patagonia Argentina circula una prensa con textos de opinión que utiliza el humorismo como recurso de confrontación, resistencia y protesta social. En este trabajo, nos interesa observar los recursos y estrategias lingüísticas en dos publicaciones periodísticas -El Cascotazo y El Mosquitomediante las cuales estos medios construyen realidad y se posicionan como actores sociales antagónicos al gobierno de turno.

Las conclusiones permiten sostener que los textos humorísticos analizados presentan las características propias del discurso agónico: constituyen contradiscursos que cuestionan el statu quo, transgreden las convenciones y las prácticas discursivas estables. Por el tenor de los recursos empleados-sarcasmo, ironía, parodia, mordacidad- estos textos devienen en humor serio.

Palabras clave: textos de opinión, estrategias lingüísticas, contradiscurso, humor serio

\begin{abstract}
At present, in the north of Argentine Patagonia is circulating a press with text opinions wich use humor as a confrontation, resistance and social protest resource. In this paper, it is important to notice the resources and linguistic strategies concerning two journalistic publications-El Cascotazo and El Mosquito-through this, this media construct reality and are establish as antagonistic social actors to the current government.

The conclusions reveal that the analized humoristic texts have the proper characteristics of the agonic discourse: they constitute contest-discourses wich question the status quo, transgress the conventions and the established discursive practices and by the resources sarcasm, irony, parody, sharpness- this texts become exponents of serious humor.
\end{abstract}

Keywords: Opinion discourse, Linguistic strategies, Contest-discourse, Serious humour 


\section{Introducción}

En la sociedad actual, y en la de todos los tiempos, el humor ha sido fundamental para la construcción de relaciones y es revelador de posicionamientos ideológicos. Aunque su estudio es relativamente reciente en el terreno de las ciencias sociales, consideramos que el análisis, desde la perspectiva de la lingüística crítica, permite una aproximación a modos singulares de posicionamiento político, social, cultural e ideológico de actores sociales que pugnan por obtener visibilidad y reconocimiento en el escenario actual. Por lo tanto, la investigación del humor discursivo se configura como un campo promisorio para explorar el poder de la palabra en el espacio público.

En la actualidad, en el norte de la Patagonia Argentina, circula un tipo de prensa activista en la que se observan textos argumentativos que utilizan el humor como recurso de confrontación, resistencia y protesta social. En este trabajo nos interesa dar cuenta de los recursos y las estrategias lingüísticas mediante los cuales, a través del humor, estos medios construyen realidad.

Las conclusiones permiten sostener quelos textos analizados presentan las características propias del discurso agónico (Angenot, 1998), es decir, constituyen contradiscursos que cuestionan el statu quo, transgreden las convenciones y las prácticas discursivas estables y, en consecuencia, por el tenor de los recursos lingüísticos empleados, devienen en humor serio.

El corpus de análisis está constituido por artículos publicados en dos medios gráficos de la región de Comahue ${ }^{1}$ : uno de circulación clandestina, El Cascotazo, y otro de circulación legal, El Mosquito. Se trata de textos que tienen la intención de crear nuevas significaciones sociales sobre los hechos y los discursos que comentan la actualidad, la política y el acontecer cotidiano. Con ello, producen un discurso herético, que socava las significaciones de los discursos hegemónicos, de las instituciones y de las buenas costumbres.

El análisis se enmarca en la nueva retórica, una perspectiva teórica que proporciona un método que consideramos eficaz para desmontar el mecanismo mediante el cual un hablante construye un artefacto textual, produce sentido y vehicula el efecto perlocutivo deseado. El objetivo de tal caracterización es determinar si el humorismo que prevalece en los mismos constituye un espacio de resistencia a las regularidades hegemónicas o si las reproduce y afianza. Además, se pretende establecer una caracterización del discurso humorístico que permita establecer analogías con tipologías textuales existentes. En este sentido, una hipótesis de trabajo es que, por los rasgos predominantes, el discurso de estos medios de prensa reúne las características del discurso político.

1. Comahue comprende el Alto Valle de Río Negro y la ciudad de Neuquén, en el norte de la Patagonia Argentina. Comahue es un término de origen mapuche que significa lugar de riqueza, también lugar donde el agua hizo daño, que puede interpretarse como una definición de valle. 


\section{Humor, humorismo, comicidad}

¿Qué es el humor? ¿Qué es el humorismo? Lamentablemente no hay consenso en cuanto a su definición y contenidos. Una somera revisión de la literatura sobre el asunto nos lleva a la conclusión de que, sobre esta materia, existe un verdadero caos terminológico y conceptual.

De una manera general, con la palabra humor nos referimos a todo aquello que hace reír. Según la Real Academia Española (RAE), el término proviene del latín umororis, "humores del cuerpo humano", de donde pasó a significar en la Edad Media el genio o condición de las personas, que se suponía causado por los "humores vitales". Pollock (2003: 46) rastrea el sentido de la palabra diacrónicamente y en diferentes lenguas y afirma que, si bien el término se resemantizó en el siglo XVI, la noción de componente humoral continúa obrando subrepticiamente permitiendo diferenciar humor de humorismo y comicidad. Por tal razón, define humor como "estado de ánimo de una persona, habitual o circunstancial, que le predispone a estar contenta y mostrarse amable, o, por el contrario, a estar insatisfecha y mostrarse poco amable”. En coincidencia con esta acepción, Garanto Alós define humor como

esa tonalidad anímica, esa atmósfera suspensiva desde la que el hombre afronta equilibradamente la realidad de la vida y de sí mismo, tanto si esa realidad se inclina o polariza hacia lo trágico, lo pesimista, lo depresivo como si lo hace hacia posturas eufóricas, excesivamente optimistas (1983: 73).

Por su parte, la RAE define humorismo como "la manera de enjuiciar, afrontary comentar las situaciones con cierto distanciamiento ingenioso, burlón y, aunque sea en apariencia, ligero. Linda a veces con la comicidad y puede manifestarse en la conversación, en la literatura y en todas las formas de comunicación y de expresión”. Tal definición nos advierte que, aunque con rasgos comunes, el humorismo no debe confundirse con conceptos afines, tales como la comicidad, y que, a diferencia del humor -estado de ánimo- es una acción, una práctica, una manifestación que se expresa mediante una determinada materialidad discursiva.

\subsection{Humorismo}

Acevedo define el humorismo como "lo cómico dignificado por la defensa de una actitud suprasocial” (1966: 281). El humorismo -según este autor- es fruto de la melancolía de un alma elevada que llega incluso a divertirse con aquello que le entristece. Si lo cómico, como veremos más adelante, con su carácter de correctivo social, representa humillación y castigo, en el humorismo, el sujeto se identifica emotivamente con el objeto de su crítica-sociedad o personaje concreto que considera ridículo o nefasto- y en esa mirada comprensiva, la actitud que motiva el discurso es tolerante y condescendiente con las debilidades humanas porque la intención, a diferencia de lo que ocurre en la comicidad, no es la de castigar el vicio 
o recompensar la virtud sino poner en evidencia actitudes reprochables. Al respecto Acevedo es terminante:

"El humorismo es una postura rebelde pero comprensiva para con la Humanidad. Muestra todo pero perdona todo. Un resentido no puede ser humorista porque es pesimista; el humorista tiene, a pesar de todo, una sonrisa de indulgencia, de comprensión y de piedad" (1966: 107). Por su parte, Lipps (1923), en Fundamentos de la Estética, establece tres clases de humorismo: el humorismo piadoso, el humorismo satírico y el humorismo irónico. El humorismo piadoso -coincidente con Acevedo- tiene como fin desconcertar al personaje absoluto que parecemos ser, dividirnos, sacarnos de nosotros, ver si desde 1 ejos o desde fuera vemos mejor lo que sucede: "Considero lo pequeño, lo mezquino, lo ridículo del mundo, pero me elevo sobre ello, sonriente, porque conservo mi fe en ese mismo mundo". El humorismo satírico opone a las contradicciones del mundo un ideal, un deber ser. Este deber ser, en cuanto constructo simbólico, aunque sea humorísticamente, delimita como verdadero un conjunto de prescripciones éticas y propone como correctas, buenas y justas, las prácticas sociales correspondientes. De esta forma, se arroga la intención de estructurar modos de subjetivación y, concomitantemente, dirigir las acciones de los individuos. Finalmente, en el humorismo irónico el sujeto es consciente del absurdo del mundo, pero no explicita cuál es el deber ser porque en definitiva no tiene ni fe ni proyectos.

\subsection{Comicidad}

La RAE define comicidad como algo "relativo a lo cómico - perteneciente o relativo a la comedia - que busca divertir o excitar la risa”. En esta definición, por lo tanto, lo que se subraya es el efecto - producir risa-y el vínculo con un tipo de espectáculo: la comedia.

Alonso de Santos (1998: 466) propone diferentes tipos de comicidad: la verbal -frases hechas, dobles sentidos, juegos de palabras-, la que proviene de situaciones -enredos, malentendidos, confusiones-, la que encontramos en algunas costumbres -anticuadas, bizarras, etc.-, la que construye un personaje -ridículo, ingenuo, etc.- De acuerdo con Berger (1997), en cambio, existirían tres variantes de la comicidad, cada una con una intencionalidad diferente. En primer lugar, este autor habla de la comicidad como divertimento, caracterizada por ser inofensiva e inocente; por ejemplo, la comicidad como consecuencia de una cadena de contrariedades o bien como producto de torpezas. El ingenio es la segunda figura delimitada por Berger. Aquí prima el juego intelectual, generalmente inducido mediante el chiste. Por último, y a diferencia de la comicidad verbal, Berger delimita una tercera figura: la comicidad con propósito agresivo.

Evidentemente, lo que diferencia la comicidad del humorismo es la finalidad. Mientras el humorismo propone una lectura diferente de lo social, impone rupturas, desplazamientos y transgresiones mediante las cuales cuestiona las respuestas habituales, la comicidad sólo busca 
entretener, amenizar, descomprimir, o bien, agredir a blancos específicos. No inquieta al poder ni pretende subvertir las verdades imperantes. A lo sumo cuestiona lo que no incomoda y remite casi siempre a defectos físicos, a tropiezos verbales, a los chismes más grotescos, superficiales y anecdóticos de los poderes débiles. La comicidad busca la risa gratificante, la liberación momentánea de las restricciones y una regresión -no patológica en cuanto controlada- a formas infantiles de pensar y actuar. Risa lúdica, no comprometida, por lo tanto, un fin en sí misma.

\section{El humorismo serio}

Actualmente se observa el auge de discursos - de la prensa y de la cultura en general- que presentan posturas polémicas acerca de la realidad. Se trata de textos de opinión cuyo objetivo es enjuiciar tal realidad, ofrecer lecturas diferentes de los fenómenos sociales y generar un discurso alternativo al discurso hegemónico. Cuando estos discursos polémicos se valen del humorismo -independientemente de que sea piadoso, satírico o irónico- se convierten en exponentes del humorismo serio, esto es, un tipo de humor que no provoca la risa-aunque puede tener un efecto cómico- sino más bien la reflexión y el análisis de los hechos desde una perspectiva crítica. Esta denominación se justifica porque, más allá del efecto risible posible, sus condiciones de producción, circulación y consumo le son propias.

El humorismo serio generalmente adscribe a un tipo de discursividad agónica (Angenot, 1998), pues lo motiva la confrontación, la palabra adversativa y la polémica. Asimismo, el humorismo serio es localizable en ciertas tipologías textuales, en particular las vinculadas con el discurso político (el manifiesto, la arenga, etc.), que implican un "posicionamiento valorativo de un individuo o grupo frente a la comunidad que integra” (Mangone y Warley, 1994: 15).

\section{El humorismo serio en la prensa}

Quienes se ocupan de los mensajes de la prensa se dan perspectivas: por un lado están los que defienden la concepción de que ésta espeja la realidady, por otro lado, están los que afirman que construye la realidad. La primera corresponde a una concepción tradicional. Se parte, desde este punto de vista, de la objetividad como clave de la actividad periodística. Evidentemente, en esta concepción de información queda oculta la actividad productiva de la noticia, la actividad de mediación de quien construye el acontecimiento. En la segunda concepción, en cambio, se trata de estudiar la actividad interpretativa de los informadores y de las organizaciones de los mass media.

Los textos de la prensa, cualquiera sea su formato, constituyen representaciones sociales (Van Dijk, 1999) porque, como modalidad de conocimiento, no reflejan la realidad externa sino que expresan la construcción de un sujeto social inserto en un campo social. Tales textos construyen, de este modo, "un mundo posible". En la construcción de un texto periodístico intervienen tres mundos distintos e interrelacionados: el mundo real, el mundo de referencia y el mundo posible. El mundo real corresponde al mundo de los acontecimientos. Los mundos de 
referencia son todos aquellos en los cuales se encuadra el acontecimiento, esto es, la enciclopedia que aporta datos para su contextualización. Por último, el mundo posible es el que construye el productor textual a partir del mundo real y del mundo de referencia escogidos.

Un texto periodístico es un proceso que se inicia con un acontecimiento, pero ese acontecimiento no es lo real sino una "realidad construida por un sujeto". Como afirman Berger y Luckman (1991: 13), la construcción social de la realidad se establece a partir de la relación entre realidad e interpretación. Eso significa reconocer que los fenómenos son reales y poseen características específicas, pero su apropiación es siempre "una apropiación mediada por un sujeto que interpreta".

Nuestro objeto de estudio son mundos posibles, realidades construidas desde una perspectiva humorística, con materialidad discursiva en la prensa, tanto convencional como alternativa.

\subsection{Prensa convencional y prensa alternativa}

Dentro de la prensa norpatagónica, ciertas publicaciones intentan diferenciarse de las tradicionales en el modo de organización -ya que no se manejan con criterios empresarialesy en las formas de difusión -no se comercializan en los circuitos tradicionales masivos.

El periódico neuquino El Cascotazo es un ejemplo de humorismo serio en la prensa alternativa. La denominamos así porque su agenda incorpora una tópica muy acotada. En cierto sentido, podría decirse que se trata también de una prensa under, ya que expresa una visión contestataria ante los valores de la cultura dominante. Manifiesta una posición política e ideológica de clase: sus autores aseguran estar del lado de los trabajadores y los explotados, y realizan una crítica radical al sistema capitalista, a la dirigencia política y a la burocracia sindical. Es prensa clandestina. Su publicación y reproducción la realiza la Red Informativa Clandestina (RIC), pero no tiene editor responsable. No cuenta con inscripción legal y sus artículos aparecen firmados con pseudónimos (por lo que también puede clasificarse como prensa anónima). Además, no se sustenta con publicidad (sus autores afirman que "con publicidad no hay libertad de prensa"), sino con "aportes solidarios de compañeros/as".

Por su parte, El Mosquito es un ejemplo de humorismo serio en la prensa convencional. Efectivamente, no presenta ninguna de las características que definen a un medio como alternativo: las críticas que se realizan apuntan a personas y situaciones concretas y nunca al sistema. Además, es un suplemento del periódico de la ciudad de General Roca-La Comunay no busca construir una agenda propia. No está expresamente comprometido con un movimiento ni causa política o social. Tampoco es un caso de prensa under, ya que no publica contenidos contraculturales. Sí es una publicación anónima, pues las notas no aparecen firmadas por sus autores, pero no es clandestina porque, como ya se dijo, es parte de un medio tradicional que cumple con todos los requerimientos legales. 


\section{Corpus y análisis textual}

El corpus seleccionado para el análisis es un conjunto de textos de las publicaciones mencionadas que circulan en la prensa norpatagónica. Tanto los artículos periodísticos de $E l$ Cascotazo como los artículos y notas de El Mosquito fueron publicados entre 2003 y 2008.

El análisis responde a una metodología cualitativa y se basa en los procedimientos esbozados por Denzin y Lincoln (1994). Estos autores proponen la construcción de teoría a partir de los datos por medio de la aplicación de procedimientos inductivos de análisis e interpretación enelestudiodeundeterminadofenómeno. Talorientaciónsuponelaobservación directa de los datos con el sustento de categorías conceptuales y lingüísticas que proveen el hilo conductor de la investigación. A través de la confrontación y comparación permanente, se procede a la sistematización de las regularidades observadas en generalizaciones. En primer lugar, entonces, se han relevado las tópicas de la totalidad de los textos que constituyen el corpus en función de los interrogantes iniciales que sirven de guía al estudio. Se procedió luego al análisis de las estrategias y los recursos ${ }^{2}$-en particular, los procesos de lexicalización, la invención de nuevas piezas léxicas y la creación de redes de significado- utilizados en la disposición textual de los títulos y los epígrafes. Asimismo, se analizaron las ilustraciones y los formatos con el objetivo de elaborar una caracterización del humorismo serio en los textos que conforman el corpus. A los efectos de lograr una sistematización de los indicadores lingüísticos que intervienen en la producción del discurso, se procedió a la localización de las unidades analíticas en el corpus, la interpretación en su contexto de producción y el desentrañamiento de su finalidad pragmática.

En síntesis, los procedimientos realizados fueron los siguientes:

- Identificación de la tópica que le da especificidad a lo humorístico en la prensa como contradiscurso (política, temas de actualidad, imaginario colectivo);

- Exploración de los dispositivos retóricos mediante los cuales el discurso humorístico se construye como discurso agónico -a través de algunos elementos paratextuales tales como títulos, epígrafes, ilustraciones y formatos-;

- Elaboración de un inventario de las estrategias y los recursos lingǘsticos más frecuentes en la construcción de este tipo de discursos;

- $\quad$ Producción de una interpretación de la lógica que rige las regularidades obtenidas para encontrar las visiones ideológicas que subyacen en tales materialidades discursivas.

2. Una estrategia discursiva constituye un plan o macroacto global -e.g. la denuncia, la manifestación de resistenciaorientado hacia una finalidad perlocutiva (van Dijk, 1997). En cambio, un recurso lingüístico refiere a un microacto con realización concreta en el nivel superficial del texto, y es, por tanto, observable en forma directa -e.g. la selección léxica, las opciones sintácticas- (Pardo, 1996). 


\subsection{El Cascotazo}

\subsubsection{La tópica}

El Cascotazo apareció en 1996 y publicó 23 números hasta 1997. Luego estuvo ausente hasta 2002. Desde entonces, se publica en forma periódica. Está impreso en blanco y negro. Tiene una tirada de 120 ejemplares y se reparte de manera personal en manifestaciones, asambleas, marchas y movilizaciones. Aparece en kioscos para la venta con periodicidad fluctuante. Como se precisara en el apartado 4.1, este medio de prensa se considera una publicación clandestina que reúne las características del periodismo activista.

La tópica de El Cascotazo se relaciona con información de actualidad acerca de los siguientes temas:

- Activismo social: actividades de jóvenes del Movimiento de Trabajadores Desocupados (MTD), Barrios de Pie, Coordinadora de Organizaciones Mapuches, etc.;

- Educación en todos sus niveles. En particular, una tópica recurrente es la Universidad Nacional del Comahue y los sucesos acontecidos en la misma durante los últimos años: la lucha por la democratización, el rechazo a los exámenes de ingreso, la inserción del Movimiento Popular Neuquino $(\mathrm{MPN})^{3}$ y su política en el ámbito académico, etc.;

- Medios: crítica a medios de comunicación masiva de la región -Canal 7, Diario Río Negro, Radio LU5, Diario La Mañana, entre otros;

- Zanón: las luchas en la fábrica de cerámica Zanón -empresa que quebró en 1999 y se convirtió en una exitosa experiencia cooperativa organizada por los mismos obreros; hoy se la conoce como Fa.Sin.Pat ("Fábrica Sin Patrones"), el Sindicato de Ceramistas, etc.;

- Justicia;

- Gobierno municipal y provincial;

- Política nacional e internacional.

\subsubsection{Estrategias y recursos humorísticos}

a. Los títulos y los autores

Los títulos de los artículos son sumamente ingeniosos. La realidad regional se construye y reconstruye constantemente a través de parodias que siempre dicen más de lo que parecen. La intertextualidad se manifiesta en su punto máximo; los elementos polifónicos otorgan una dimensión polémica al discurso y revelan la disputa ideológica entre el medio de prensa y la posición oficialista. Es precisamente entre la catarsis y la provocación donde se dibuja una

3. El Movimiento Popular Neuquino es un partido político de carácter regional -liderado por Felipe Sapag-que ha gobernado la provincia de Neuquén desde hace medio siglo. 
reflexión crítica del orden político imperante. No es posible leer este material sin reflexionar acerca de los temas planteados.

Los artículos aparecen firmados con seudónimos. De este modo, se diluyen las identidades de los productores del texto. En su editorial “¿Cagones?”, del número cuatro, los autores proporcionaban una explicación para el anonimato. Decían: "no creemos en la justicia burguesa ni en la falsa libertad de opinar que nos exige cara descubierta”. Al periódico (8300) - que se publica en la ciudad de Neuquén- le aseguraron que "daremos la cara luego de realizarnos las últimas cirugías estéticas correspondientes”. Las muestras a continuación revelan los singulares seudónimos escogidos por los autores de los textos.

(1). Zanon. Tiempo de definiciones (Año 1. No 2)

Autor: Luisa A. Dobe

(2). Guerra Cloacal en el MPN (Año 1. No 4)

Autor: Inodoro M. Ado

(3). 8 de marzo: día de la mujer. ¿Qué pito festejamos? (Año 1. No 4)

Autor: La Carmen

(4). ¡Maravilloso para el progresismo! ¡El Rio Negrero ${ }^{4}$ denuncia el gasto público en NQN! (Año 1. No 6)

Autor: Lalo Cura

(5). El Cascotazo Enterteinment presenta "Escenas de las marchas cotidianas" (Año 1. No 8) Autores: Jorge Irreal y Viviana Callosa

(6). Administradores de escuelas (Año 2. No 10)

Autor: Paula Tina Mente

Con frecuencia los títulos recurren a la estructura interrogativa con una pregunta alternativa, como se observa en (7), (8) y (9). La utilización del título de la conocida obra de Orwell en (10) evoca un mundo posible en el que los valores se han alterado y subvertido. Finalmente, en (11) y (12) la inclusión de letras y piezas léxicas en paréntesis genera desplazamientos de sentido que provocan la crítica y el efecto humorístico característico de estos textos.

(7). ¿ ¿Subsecretaría de acción social o de explotación social? (Año 1. No 5)

Autor: Tristán (el de la mirada distinta) ${ }^{5}$

(8). ¿Examen o control de ingreso? (Año 3. No 15)

Autor: Eli Minado de Carrera

(9). Periodismo ¿cuarto poder o cuarto de poder? (Año 2. No 12)

4. El título del artículo refiere al Diario Río Negro y a los intereses ocultos de este medio al denunciar gastos realizados por los integrantes de la Legislatura neuquina y el Poder Judicial.

5. Referencia a Tristán Díaz Ocampo, actor cómico argentino que padece estrabismo. 
Autor: Chiche Gelblung ${ }^{6}$

(10). Rebelión en la granja (Año 3. No 14)

Autor: Pichón A. Vícola

(11). (J)Oda a la responsabilidad (Año 3. No 18)

Autor: Carmen Argibay Vda. de Zafaroni

(12). Abrazos muy (poco) convencionales (Año 3. No 18)

Autor: Anónimo

\section{b. Los epígrafes}

El epígrafe es una cita, verdadera o atribuida falsamente a un autor. También puede ser atribuida a un autor imaginario, por lo tanto, anónima. Funciona como comentario del título, como anexo justificativo, comentario al texto -al precisar indirectamente la significación del mismoo de padrinazgo indirecto (cuando lo importante no es la cita en sí misma, sino la identidad de quien lo dice). El epígrafe, conjuntamente con el título, estimula al lector a elaborar hipótesis sobre el contenido del texto. Como observamos en las siguientes muestras, todos los epígrafes que siguen son humorísticos y funcionan como intertextos de los títulos y los respectivos artículos.

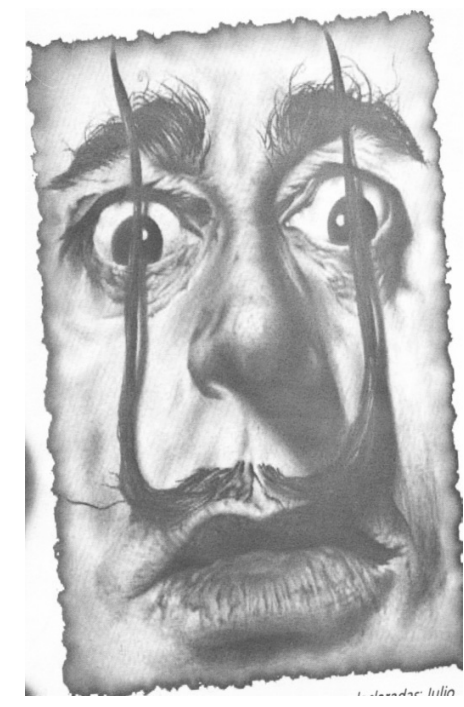

Figura 1.

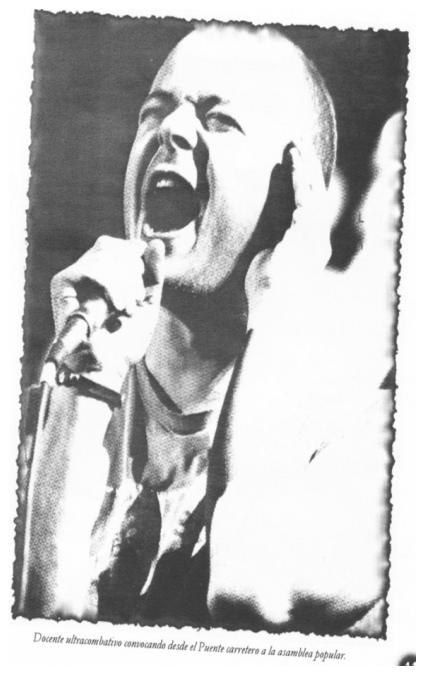

Figura 2.

6.Samuel "Chiche" Gelblung es periodista en espacios radiales y televisivos. Se caracteriza por fusionar periodismo con show en informes de corte sensacionalista. 
(1). Guía práctica para ateos y creyentes en crisis (Año 1. No 6)

(El artículo plantea las consecuencias de la religión y sus instituciones, y proporciona

"herramientas" para ayudar al lector a resistir los embates de la religión)

Autor: Blas Femia

Epígrafe: "El infierno está encantador" Judas

(2). Ser ladrón no duele, lo que duele es que te roben tanto (Año 1. No 7)

(El autor "enseña" a robar frutas y verduras. Además, propone estrategias para no ser descubierto)

Autor: Robocop

Epígrafe: "Hasta la verdura siempre" Chef Guevara

(3). Cien años de ebriedad (Año 2. No 13)

(El artículo describe la "maratón” del gobierno neuquino por realizar múltiples actos al cumplirse el centenario de la ciudad)

Autor: Gabriel García Belsunce

Epígrafe: "Sayhueque no existís" Repsol

\section{c. Las ilustraciones}

Las ilustraciones que acompañan los textos realzan el efecto humorístico de los artículos. Se observan interesantes interjuegos en los que se utilizan imágenes reconocidas que se reinterpretan en el contexto actual o contemporáneo. A continuación se incluyen algunos ejemplos de imágenes que han sido resignificadas en función de la tópica que se aborda en el artículo. En (1), el siguiente texto acompaña la imagen: Dueño de Río Negro y otras empresas no declaradas: Julio Rajneri con los pelos de punta, escribiendo sus estúpidas pero eficaces editoriales que salían en medio de la huelga docente (Ilustración que acompaña la nota: Feos, sucios y malos. La verdadera imagen de los docentes en los medios de comunicación. Autores: Pancho Casado y Hamburguesa Soltera (Año 6. ${ }^{\circ} 21$ ). En (2) se lee el siguiente texto: Docente ultracombativo convocando desde el Puente carretero a la asamblea popular. Esta imagen acompaña el artículo La obsesión por el traidor. Patología del trotskismo y otras vanguardias afines. Autores: Raúl Ceibo y Roque Bracho (Año 6. ${ }^{\circ} 21$ ). Finalmente, (3) ilustra la tapa del periódico con el titular ¿Qué carajo les pasa a los estatales? (Año 3. ${ }^{\circ} 17$ ).

El texto que acompaña el fotomontaje de la conocida imagen de La maja desnuda de Goya en (3) se reproduce a continuación: "Docente de Matemática que por los bajos salarios se ve obligada a complementar sus ingresos mediante la prostitución. Maestra en el arte del sexo, aquí la vemos trabajando en la Dirección de la EPET 17. La imagen fue cedida por el Director."

7. Escuela Pública de Educación Técnica (N. del E.). 


\section{d. Los formatos}

Los autores recurren a la parodia de formatos discursivos. El más utilizado es la entrevista (ficticia) con autoridades del gobierno de Neuquén (Pechi Quiroga, el intendente; “Toti” Manganaro, el ministro de Seguridad; Jorge Sapag, el nuevo gobernador de la provincia electo en 2007, etc.). Otros formatos que se emulan o parodian son: recetas de cocina, correo sentimental, reseñas de libros y reseñas de películas. También se imita el estilo de tipos textuales tales como un manifiesto (Manifiesto para ladrones de supermercados) en el que el autor proporciona una justificación moral para robar comida sin culpa, o la presentación de resultados de prácticas deportivas (Clausura 2004. Estudiantes: 2 - Sobich: 0) en alusión al resultado de la toma de la Universidad Nacional del Comahue en el año 2004.

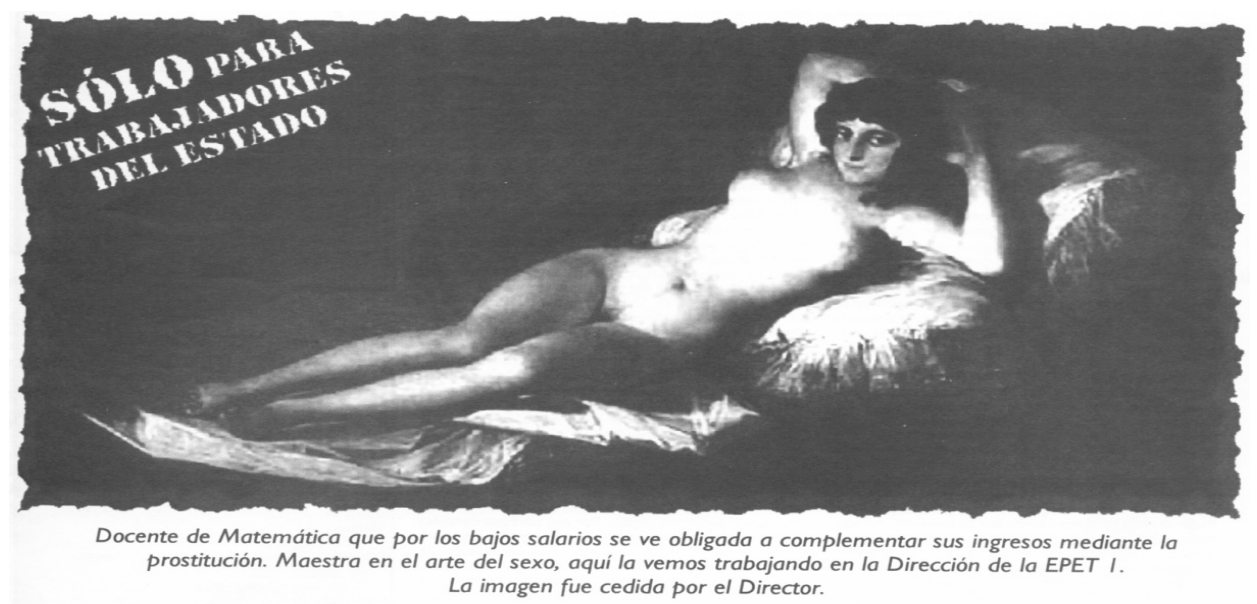

Figura 3.

Otros recursos lingüísticos incluyen juegos de palabras con doble sentido o creación de nuevas piezas léxicas. Por ejemplo, se denomina Diario Río Negrero al Diario Río Negro, Diario La Maraña al Diario La Mañana, Canal hijunagransiete al Canal 7, Jorge Tomar Sobisch o Jorge Zoobicho en referencia a Jorge Omar Sobisch - ex-gobernador de la provincia de Neuquén y candidato a la presidencia de Argentina en 2007-. Además, se observa la combinación del registro neutral o formal con piezas léxicas de registro vulgar (buchonear, carnero, la gilada, chorear, etc.), como así también la utilización de léxico con connotaciones diferentes de las canónicas, metáforas y asociaciones.

Todos los recursos relevados (los títulos, los seudónimos de los autores, los epígrafes, la gráfica y los formatos) se convierten en herramientas para construir un adversario y poner en evidencia contradicciones, desatinos, doble moral de dirigentes y funcionarios a través de un humor crítico y subversivo. De esta forma, se intenta subvertir prácticas, órdenes y jerarquías, escapar de las convenciones del lenguaje y alterar las representaciones instaladas en el imaginario colectivo a través de la producción de significados alternativos. 


\subsection{El Mosquito}

\subsubsection{La tópica}

El Mosquito es un suplemento dentro del periódico La Comuna, que se publica en la ciudad de General Roca desde agosto de 2003. Este periódico sale los días lunes y jueves de cada semana, pero El Mosquito sólo aparece los días jueves. Además de la versión en papel, esta publicación tiene su espacio en la red, ya que el suplemento se encuentra disponible en la página de Internet de La Comuna y también en el blog del mismo nombre. Los editores -que, al igual que en $E l$ Cascotazo, son anónimos - definen al suplemento como un "aguijón textual" y sostienen que el objetivo es que "la risa del lector sirva para la catarsis y la toma de posición frente a la realidad". El nombre escogido está inspirado en la publicación semanal homónima editada en Argentina desde 1863 hasta 1893. Ésta fue la primera revista profesional e independiente que recurrió a la caricatura como herramienta principal para expresar sus críticas mordaces, satíricas y burlescas a los miembros del poder político del momento.

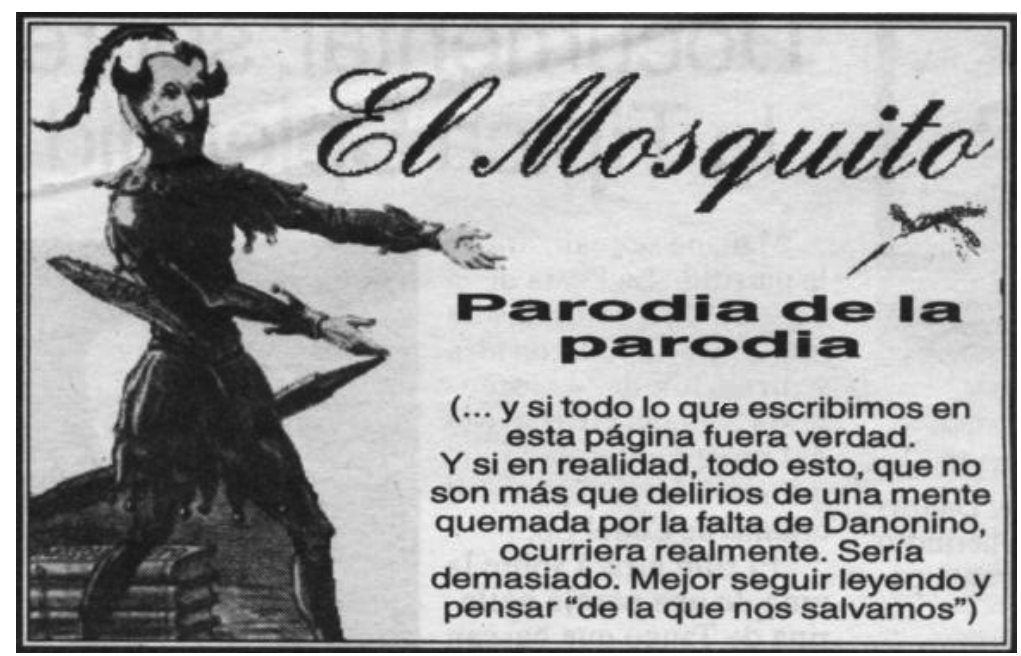

Figura 4.

En El Mosquito, las tópicas abordadas se relacionan con la política de la región y los medios de comunicación. Los artículos son breves y en su gran mayoría consisten en ataques directos al gobierno local, provincial y nacional, a los medios de comunicación oficialistas y a las agrupaciones estudiantiles de derecha. Se denuncian con implacable rigor las manipulaciones políticas, la falta de contenido ético de algunos gobernantes y las mezquinas ambiciones personales que debilitan su actuación política. 


\subsubsection{Estrategias y recursos humorísticos}

\section{a. Los titulos y los autores}

Las notas son anónimas ya que notienen autor responsable ni seudónimo alguno. El tratamiento lúdico de la realidad se observa con claridad en la presentación que identifica el suplemento, la cual se reproduce a continuación ${ }^{8}$ :

Los títulos resultan ingeniosos e invitan a la reflexión desde la perspectiva humorística. Veamos algunos ejemplos, en los que también transcribimos partes de las notas:

\section{(1) Neuquén es con fianza}

La provincia de Neuquén hizo un llamado a licitación para definir qué se hará con el futuro político del gobernador Jorge Omar Sobisch. El que alguna vez soñara con ser la mano derecha que aferrara el poder en la Casa Rosada, hoy anda con los bigotes alicaídos, con la mirada baja, pateando piedritas para ver si encuentra a quién más echarle la culpa por el asesinato del docente Carlos Fuentealba9. "Quedé más solo que el siempre bien recordado y admirado Augusto Pinochet en el día del amigo. Lo llamé a Macri para ver si me daba su apoyo y me respondió que prefería abrazar a un cartonero antes que hundirse conmigo...”(12/04/2007).

\section{(2) Desafío en la azotea}

Sorprendió hace unas semanas una noticia por la cual se supo sobre el misterioso hallazgo de un escrito dentro de la cabeza de una escultura en la Basílica de San Francisco, en Buenos Aires. Tras este enigmático descubrimiento, los mismos restauradores fueron convocados para un desafío aun mayor. Desde el Congreso de la Nación fueron citados para ver si pueden encontrar algo interesante dentro de la cabeza del diputado rionegrino Hugo "Cacho" Cuevas. "Sabemos que será una tarea tan difícil como encontrar vida inteligente en otros planetas, pero si el ser humano ha logrado vencer al yermo desierto para tener estos valles, cómo no vamos a rescatar una idea del marote/cascote de este radical que taaan bien nos representa y del que taaaan orgullosos se sienten los rionegrinos de bien”, destacó uno de los restauradores y se fue a afilar el cincel. (10/05/2007) operativo que buscaba impedir el corte de una ruta como medida de protesta en el marco de una huelga del sindicato docente ATEN (Asociación de Trabajadores de la Educación del Neuquén). 


\section{(3) Un campo de opiniones...}

¡Qué kilombete que se le armó al gobierno con el paro del campo ${ }^{10}$ ! Ya que estamos nos interesa su opinión. ¿En qué anda su cabecita, cómo se mueven las neuronas para definir su postura sobre este conflicto?

Para usted ...

1. la protesta no le llega a las entrañas porque las penas son de nosotros, las vaquitas son ajenas.

2. hay que repartir las vacas y las lechugas entre todos y que cada uno se haga cargo de su campito.

3. los productores son la nueva oposición a un gobierno autoritario que quiere quedarse con toda la papota y no repartirla.

4. $\quad$...

Votos y botox en www.periodicolacomuna.com.ar/Mosquito. Habrá premios sorpresa el día en que se socialice la tierra y todos seamos iguales, o al menos parecidos. $(27 / 03 / 2008)$

Como se observa en estos textos, de las estrategias y recursos humorísticos que se utilizan con mayor frecuencia se destacan las figuras de agresión a la clase dirigente -mordacidad, sarcasmo, ironía - para cuya interpretación se requiere el conocimiento del contexto como en toda decodificación de enunciados humorísticos que utilizan los conocimientos compartidos del locutor y del interlocutor.

Además, los autores recurren también a la modificación de los nombres de los actores sociales (Kichinet, Veranete, Kaiz y Soretobisch en lugar de Kirchner, Verani, Saiz y Sobich); la alusión a características personales como, por ejemplo, el peinado (Miguel "peinatequesalimos" Pichetto o, a partir de 2008, Miguel "güinaesapeinada" Pichero en referencia al senador nacional definido por El Mosquito como "la espada con poco filo del kirchnerismo") o algún rasgo distintivo, e.g. la sonrisa permanente (“Carlos ¡Sonría!” en lugar de Carlos Soria, actual intendente de la ciudad de General Roca).

Otras estrategias frecuentes son: la utilización de juegos de palabras con doble sentido ("Raja Morada” por Franja Morada ${ }^{11}$ ); la inclusión de citas ficticias (" 'Vamos por partes', dijo el radicalismo cuando empezó a despedazar la provincia” -representantes del partido radical han gobernado Río Negro durante los últimos veinte años); la comparación de seres humanos con exponentes del reino animal ("Viedma: Entre pavos y faisanes. Los pajarones del gobernador", título de una nota que hace referencia a los "colaboradores" del gabinete del gobernador de Río

10. A mediados de marzo de 2008 se inició el paro del campo, una medida de fuerza con cortes de ruta en contra de las retenciones a las exportaciones impuestas por el Gobierno Nacional.

11. Partido político universitario alineado con la UCR (Unión Cívica Radical). 
Negro, Miguel Saiz ${ }^{12}$, y denuncia la inoperancia y la falta de compromiso con la labor pública); la exageración intencionada con el objetivo de plasmar en el interlocutor una imagen difícil de olvidar ("todos los caminos conducen a Roca").

Una de las secciones recibe el nombre Insectirrogantes. En este apartado, los autores formulan preguntas ácidas que interpelan al lector. Algunas muestras se presentan a continuación:

(1) ¿No es buenísimo que el candidato radical en Choele Choel sea Ricardo Calvo, teniendo en cuenta que la UCR ha pelado las finanzas de la provincia?

(2) ¿Para usted el secretario general de UPCN ${ }^{13}$ (Unidos Para Currar Nuevamente), Juan Carlos Scalectrix -apellido real: Scalesi-, se opuso al cambio de horario para defender a los trabajadores o fue porque no le gusta que le cambien la rutina a la hora de chuparle las medias al gobierno?

(3) Cuando escucha que el intendente de la estancia dice que en el 2007 hubo un superávit de cuatro palos, ise pone contento porque eso significa que es un tipo eficiente o le da miedo que decida gastar esos palos en los lomos de los que no piensan como él?

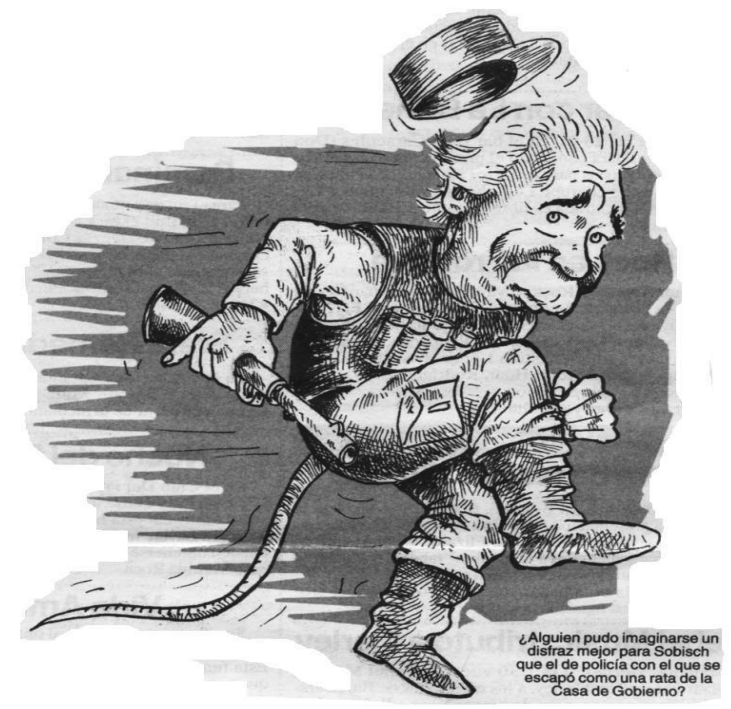

Figura 5 .

\section{b. Las ilustraciones}

El Mosquito recurre a caricaturas para acompañar las notas. Este tipo de humor gráfico, que se vale de la exageración y la deformación, contribuye a generar una diversidad de lecturas. En

12. Miguel Saiz fue elegido gobernador de Río Negro en dos oportunidades. Pertenece a la Unión Cívica Radical, partido que ha gobernado la provincia durante los últimos 25 años.

13. Organización gremial que nuclea empleados públicos nacionales, provinciales y municipales. 
mayor o menor grado, las ilustraciones se convierten en herramientas eficaces al servicio de la crítica periodística al transmitir un mensaje de un modo más claro y contundente que un discurso (Antezana, 2005). Los recursos utilizados tienen un denominador común: minimizar la exigencia de que un hecho en particular sea tomado con solemnidad y permitir, de este modo, la interpretación humorística.

Las caricaturas que conforman la muestra que sigue a continuación, destacan algún rasgo del personaje que retratan, al que deforman con la finalidad de crear el efecto humorístico. Observamos a Jorge Sobisch transformado en una rata en (1), acompañando la nota Neuquén es con fianza (parcialmente reproducida en el apartado anterior) con el siguiente comentario: "iAlguien pudo imaginarse un disfraz mejor para Sobisch que el de policía con el que se escapó como una rata de la Casa de Gobierno?”. En (2), vemos al intendente Carlos Soria - con el realce de su carácter gruñón y autoritario- recibiendo a los candidatos a pasantías en la Municipalidad de General Roca. La imagen se complementa con el siguiente texto: "Se abre la tranquera y retoños de abogados pueden entrar a la estancia que regentea Carlos ¡Sonría!”. Finalmente, (3) muestra el actual senador nacional Pablo Verani -con rasgos que revelan una clara analogía con el conocido personaje de la serie El Santo- en una nota que se titula Frases de película, en la que se le atribuye una frase de El Padrino al personaje de la caricatura ("Voy a hacerle una oferta que no podrá rechazar").

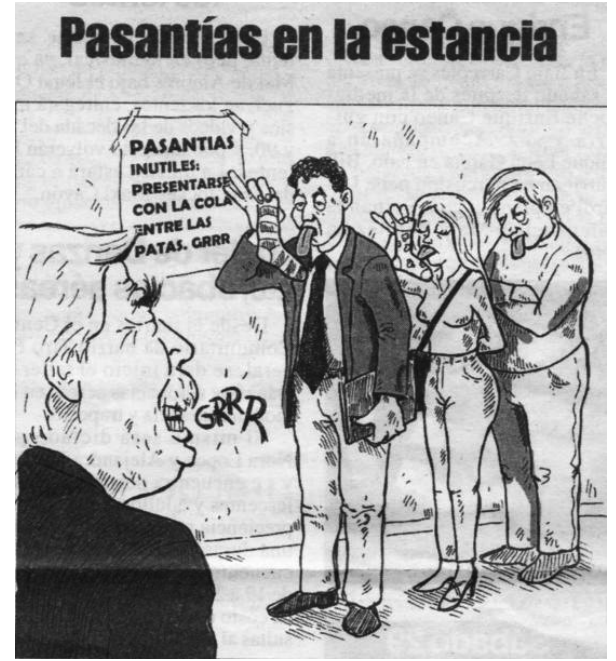

Figura 6.

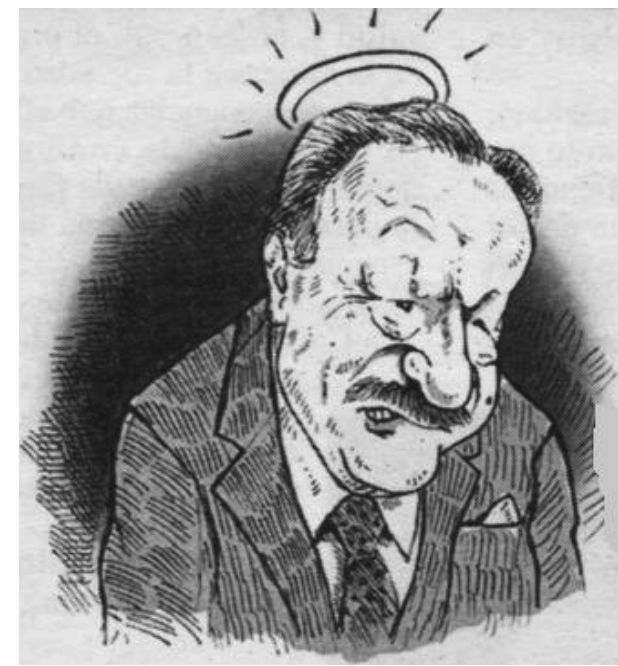

Figura 7.

El humorgráfico despliega la capacidad de síntesis del artista, transmite una determinada representación de conflictos sociales y orienta al lector en la búsqueda de nuevas significaciones. Por ello, la caricatura permite instaurar la crítica de la realidad desafiando los límites del poder y de la realidad misma. Constituye, así, un modo alternativo de expresar una opinión. 


\section{c. Los formatos}

En la formulación de los títulos de cada nota, a menudo se recurre a la parodización de formatos conocidos, por ejemplo el de Buscado -que incluye la foto de algún político y el texto que ofrece cuantiosas recompensas-, el de las placas del canal Crónica $\mathrm{TV}^{14}$, con distintos titulares según el tema, o secciones de revistas tales como "frases de película", "el estreno del mes", "encuestas y sondeos de opinión”, entre otros formatos.

\section{Conclusiones}

En este trabajo se ha tratado de demostrar que el discurso humorístico mediático -al menos en la región norpatagónica- reúne las condiciones del humorismo serio contestatario, que ofrece lecturas diferentes de lo social, impone rupturas, desplazamientos y transgresiones. Este tipo de humorismo tiene la intención evidente de crear nuevas significaciones sociales sobre los temas de actualidad y las construcciones del imaginario colectivo. Con ello, produce un discurso crítico y subversivo, para nada complaciente, que busca socavar los mensajes de los discursos hegemónicos.

A pesar de las diferencias en las condiciones de producción -El Cascotazo se enmarca en el periodismo clandestino y activista, El Mosquito se encuadra en el periodismo convencionalestos medios ofrecen formas similares de contradiscursos. Cabe destacar que un contradiscurso se define por su capacidad para quebrar silencios de dominación, por subvertir prácticas, escapar de las convenciones del lenguaje, quebrar fronteras de representaciones instaladas en un imaginario colectivo contra las que se lucha a través de la producción de significados alternativos. Y es justamente éste el objetivo que estas publicaciones persiguen: movilizar al público que las consume e invitar a la reflexión y la resistencia.

Tanto El Cascotazo como El Mosquito desarrollan tópicas relacionadas con aspectos de la vida cultural, social y política de la región. Uno de los recursos léxicos que utilizan ambos medios para marcar la apertura del espacio ficcional es la invención de nombres propios. En la mayoría de los casos, los personajes aludidos se presentan ridiculizados a través de asociaciones insólitas que surgen de la analogía entre términos próximos en el plano semántico. El humor se produce por el choque cognoscitivo entre dominios que no coinciden en el mundo real; el discurso resultante resulta cohesivo pero incongruente, y tal incongruencia crea el efecto humorístico.

Ambos medios recurren a la parodia en la materialización discursiva de los textos, estableciendo relaciones intertextuales con otros en forma permanente, bien sea a través de la alusión o de la mención explícita. Podría hablarse de una relación de espejo entre un texto nuevo y otro ya existente. Respecto de los formatos, en ambos medios se observa la vulneración de ciertas características y normas propias de los géneros periodísticos. El efecto humorístico 
está garantizado por tal violación de convenciones o principios. Tal como sostiene Gómez Capuz, "el humor se produce quebrantando el código, a través de la transgresión consciente, deliberada, constante y sistemática de los mecanismos que rigen el normal desarrollo de la interacción comunicativa cotidiana” (2002: 75).

Finalmente, los recursos lingüísticos más utilizados en las publicaciones analizadas son el juego de palabras de doble sentido -silepsis-, los términos polisémicos, la metáfora, la exageración, los cambios bruscos de registro - de un tono excesivamente formal a uno informal, o viceversa- y la ironía, que en estos textos está típicamente ligada al escepticismo y el desacuerdo. Por su parte, las caricaturas se constituyen en expresiones valorativas que, al realzar o deformar a los referentes, materializan una opinión de un modo alternativo y revelan la posición del medio de prensa respecto de la realidad en forma implícita. Éstos constituyen los mecanismos más frecuentes en la creación de efectos humorísticos en las publicaciones relevadas.

Además de exhibir un repertorio de procedimientos retóricos que le son propios, el humor es una forma de posicionamiento ideológico ante la realidad. En los textos analizados, lo que parece ser una frivolización lúdica se constituye en un modo de poner en tela de juicio valores y normas sociales, transgrediendo hasta el propio código lingüístico a través de la violación de aspectos pragmáticos - por ejemplo, mediante la semántica de los implícitos. Como sostiene Bajtín (1981), el humor cumple una función de crítica social, por lo tanto es altamente positivo y su expresión se constituye en un acto de libertad y subversión a las imposiciones.

En los medios gráficos analizados - cuyos artículos denuncian las contradicciones, las hipocresías, las mediocridades y la corrupción que advierten en la región-sus autores se limitan a desenmascarar la incompetencia de políticos y funcionarios y a ridiculizar referentes del mundo sindical, académico o periodístico, en una especie de desesperada catarsis emocional. Se trata, según la clasificación de Lipps, de un humor irónico en el que la ironía se sitúa al nivel de la palabra o de la frase, con dobles sentidos, juegos de palabras y citas parafraseadas que conforman una red de múltiples relaciones intertextuales con textos a los que remiten o aluden en forma permanente. El mensaje profundo es serio: estos medios constituyen la voz de la resistencia. Autocalificados como "agitadores culturales", los articulistas de El Cascotazo manifiestan que los productores de los textos "son conscientes del absurdo del mundo, pero no explicitan cuál es el deber ser porque en definitiva no tienen ni fe ni proyectos”. En uno de sus editoriales, expresan: "una deuda pendiente que no tenemos saldada -que creo que nunca vamos a saldar- es que no tenemos un proyecto de la sociedad. No tenemos un programa político como tienen otras organizaciones. Lo que sí tenemos claro es que hay cosas que queremos y hay cosas que no queremos".

Tanto El Cascotazo como El Mosquito nacen de la necesidad de expandir las fronteras de lo decible desde la lógica del poder, de expresar públicamente otras ideas, de nombrar realidades silenciadas, de legitimar voces y verdades que una parte de la sociedad conoce y otra niega, por 
omisión o por complicidad. Destinados a un público claramente sesgado desde la enunciación, se erigen en una forma de resistencia a la ideología hegemónica. Desde la subversión de los cánones discursivos, en un intento de validación de nuevas identidades sociales, resignifican algunas matrices culturales propias del imaginario neuquino y rionegrino. De este modo, se constituyen en elementos de unión y de comunión en una sociedad cohesionada desde el discurso hegemónico pero disgregada en sus prácticas cotidianas y públicas. Desestructurar el orden y traspasar fronteras equivale a abrir un canal de nuevas circulaciones de discursos en una sociedad agitada y en cambio permanente, donde la necesidad de la construcción colectiva da como resultado una preocupación por el presente como fruto primero, aunque sea desde el desencanto.

\section{Referencias bibliográficas}

Acevedo, E. (1966). Teoría e interpretación del humor nacional. Madrid: Editora Nacional.

Albaladejo, T. (1989). Retórica. Madrid: Síntesis.

Alonso de Santos, J. L. (1998). La escritura dramática. Madrid: Castalia.

Angenot, M. (1998). Interdiscursividades. De hegemonías y disidencias. Córdoba: Universidad Nacional de Córdoba. Argentina.

Antezana, L. (2006). «La caricatura de prensa chilena». Documentos del Centro de Estudios de la Comunicación. No 3. Universidad de Chile, pp. 20-40. Obtenido desde http://www. comunicacion. uchile.cl/docs/CECOM_CUAD_3_2006.pdf

Bajtín, M. (1981 [1995]). Estética de la creación verbal. México: Siglo Veintiuno.

Barei, S. et al. (2000). Politicas del humor en la Argentina de los 90: publicidad, diario digital, cultura juvenily literatura. Córdoba: Universidad Nacional de Córdoba.

Berger, P. (1997). La dimensión cómica de la experiencia humana. Barcelona: La Campana.

Berger, P. y Luckman, T. (1991). La construcción social de la realidad. Buenos Aires: Amorrortu.

Denzin, N.K. y Lincoln, Y.S. (1994). «Entering the field of qualitative research». En: Handbook of Qualitative Research. California: Sage Publications, pp. 1-17.

Garanto Alós, J. (1983). Psicología del humor. Barcelona: Herder.

Gómez Capuz, J. (2002). «Mecanismos del lenguaje humorístico». Análisis del discurso oral. № 5. Madrid: Editorial Arco Libros, pp. 75-101.

Lipps, T. (1923). Los fundamentos de la estética. Madrid: Biblioteca Internacional de Psicología Experimental. Daniel Jorro Editor.

Mangone, C. y Warley, J.; eds. (1994). El discurso político del foro a la TV. Buenos Aires: Biblos.

Moliner, M. (1977). Diccionario de uso del español. Madrid: Editorial Gredos.

Pardo M.L. (1996). Derecho y lingüística. Cómo se juzga con palabras. Buenos Aires: Nueva Visión. 
Piscitelli, A. (1995). Ciberculturas. Buenos Aires: Paidós.

Pollock, J. (2003). ¿Qué es el humor? Buenos Aires: Paidós.

Real Academia de la Lengua (2001). Diccionario de la lengua española. Madrid: Espasa-Calpe (22a ed.). van Dijk, T. A. (1997). Racismo y análisis crítico de los medios. Barcelona: Paidós. (1999). Ideología. Barcelona: Gedisa.

Verón, E. (1987). «La palabra adversativa. Observaciones sobre la enunciación política». En: El discurso político. Lenguaje y acontecimientos. Buenos Aires: Hachette. 